\title{
O conhecimento e a utilização de filtro solar por profissionais da beleza
}

\author{
Level of awareness and the adequate application of sunscreen \\ by beauticians
}

\author{
Diógenes Aparício Garcia Cortez ${ }^{1}$ \\ Érica Simionato Machado ${ }^{1}$ \\ Sonia Cristina Soares Dias Vermelho ${ }^{2}$ \\ Jorge Juarez Vieira Teixeira ${ }^{3}$ \\ Lucia Elaine Ranieri Cortez ${ }^{1}$
}

${ }^{1}$ Programa de PósGraduação em Promoção da Saúde, Centro Universitário de Maringá. Av. Guedner 1610, Jardim Aclimação. 87050-900 Maringá, PR, Brasil.dagcortez@uem.br ${ }^{2}$ Núcleo de Tecnologia Educacional para a Saúde, Universidade Federal do Rio de Janeiro. Rio de Janeiro RJ Brasil.

${ }^{3}$ Programa de Pós-

Graduação em Biociências e Fisiopatologia, Universidade Estadual de Maringá. Maringá PR Brasil.

\begin{abstract}
The scope of this research was to establish the level of awareness of beauticians regarding the importance of the application of sunscreen and to identify whether their patients had been properly instructed by these professionals. It involved a descriptive and exploratory study with interviews applying qualitative methodology among 30 beauticians. Data were gathered using the semi-structured interview technique in Maringá, in the southern state of Paraná. The data were analyzed using Atlas.ti software after applying quantitative analysis and response classification. Of those interviewed, $83.33 \%$ had a degree in Aesthetics, 20\% attended ongoing training activities on sunscreen and $73.17 \%$ acquired sunscreen for its quality, though $86.67 \%$ were not familiar with sunscreens with natural anti-free radical components. Of those interviewed, $80 \%$ had never treated patients with skin cancer, though they reported having knowledge of care in relation to sun exposure and how to use the sunscreen and the relationship of these practices with the disease. The results showed that the recommendations and use of sunscreen by beauticians and users has been conducted in an adequate and conscientious manner.
\end{abstract}

Key words Skin cancer, Esthetics, Sunscreens, Aging, Quality of life
Resumo O objetivo desta pesquisa foi verificar o nivel de instrução dos profissionais da área de estética em relação à utilização de filtro solar, $e$ também identificar as orientações que estes passam aos seus pacientes. O estudo foi exploratóriodescritivo, adotando a metodologia qualitativa ao entrevistar 30 profissionais da área. A coleta de dados foi feita por entrevistas semiestruturada na cidade de Maringá (PR). Os dados foram tratados com o software Atlas.ti a partir análise qualitativa e categorização das respostas. Dos entrevistados, 83,33\% possuíam graduação em Estética, 20\% participaram de atividade de formação continuada sobre o assunto, 73,17\% adquirem o protetor solar pela qualidade, e $86,67 \%$ não conhecem filtros solares com componentes antirradicais livres naturais. Dos entrevistados, $80 \%$ nunca atenderam pacientes com câncer de pele, porém mencionaram ter conhecimento sobre os cuidados em relação à exposição solar e à forma de utilização do filtro solar e a relação dessas práticas com a doença. Os resultados mostraram que a indicação e o uso de filtro solar por profissionais da beleza vêm ocorrendo de maneira adequada e consciente.

Palavras-chave Câncer de pele, Estética, Filtro solar, Envelhecimento, Qualidade de vida 


\section{Introdução}

O tema deste artigo está inserido na problemática do envelhecimento enquanto questão de saúde pública que precisa ser investigada de modo a se criar alternativas para enfrenta-la. Neste sentido, a pesquisa parte do entendimento de que o envelhecimento é um processo multifatorial, multicausal e heterogêneo, marcado pela presença de alterações fisiológicas e de mudanças corporais ${ }^{1}$, as quais predispõem o indivíduo a doenças como hipertensão, diabetes e câncer. Esse processo é marcado pela presença de alterações fisiológicas e por mudanças corporais ${ }^{1}$ decorrentes do envelhecimento fisiológico (intrínseco) e/ou envelhecimento causado por fatores externos (extrínseco), como a poluição, a radiação solar, o tabaco, entre outros.

Uma das alterações que o envelhecimento provoca diz respeito à pele, a qual sofre ao longo da vida a ação dos fatores intrínsecos e extrínsecos. Neste sentido, procuramos analisar a forma como os profissionais da estética lidam e orientam seus pacientes em relação ao Filtro Solar (fator extrínseco), que ajuda a prevenir doenças de pele, tais como o câncer, que em muitos casos é causado pela exposição aos raios.

Entre os fatores externos, a exposição solar compõe o principal desencadeador do câncer de pele, sendo que o tipo não melanoma é a patologia mais incidente no Brasil ${ }^{2}$. Estudo realizado por Souza et al. ${ }^{3}$ revela que entre janeiro de 2000 a dezembro de 2007, somente no Estado de São Paulo, foram diagnosticados 42.184 casos de carcinoma basocelular e de carcinoma espinocelular. Estes geraram um gasto ao Sistema Único de Saúde da ordem de R \$37.773.449,92 para o tratamento de câncer de pele tipo não melanoma e $\mathrm{R} \$ 33.012 .725,10$ para o de 2.740 pessoas diagnosticadas com melanoma cutâneo. Somente esses números, indicam a importância de medidas preventivas para que a população obtenha hábitos que evitem o surgimento dessas neoplasias.

A prevenção e o diagnóstico precoces desta neoplasia são fundamentais na redução da sua morbimortalidade e, consequentemente, a diminuição do impacto na saúde pública ${ }^{4}$. Os hábitos que devem ser incluídos diariamente para a redução da incidência do câncer de pele são: evitar a exposição direta ao sol, utilizar chapéus, óculos solares e vestir-se adequadamente. Outra forma de prevenção do câncer de pele é o uso de filtro solar ${ }^{5}$.

Em estudos sobre a eficácia dos filtros solares na prevenção de câncer de pele, Schalka e Reis ${ }^{6}$ afirmam que estes, sejam fotoprotetores tópicos ou protetores solares, são capazes de reduzir os efeitos deletérios dos raios solares por sua capacidade de interagir com a radiação existente. Porém, para uma proteção eficaz não basta somente aplicar o produto, outros cuidados são necessários, como, por exemplo, devem ser utilizados diariamente respeitando seu fator de proteção solar (FPS), além disso, deve-se ter cuidados em relação à quantidade aplicada, aos horários de reaplicação e às condições de armazenamento.

Pode-se perceber que recentemente tem crescido o número de institutos, centros de estética e salões de beleza, o que pode refletir duas preocupações: o desejo de manter-se belo(a), o que nos remete à dimensão estética, e o cuidado do corpo na perspectiva da saúde. Neste sentido, ações de prevenção e promoção da saúde, tais como a utilização consciente do filtro solar, a procura por formulações fotoprotetoras com componentes naturais e a busca de tratamento apropriado, devem ser cada vez mais estimuladas e exploradas pela população.

Para desenvolver essas ações junto à população, é importante a ação de profissionais capacitados atuando nos centros de saúde e de estética para que se possa ter segurança em relação ao diagnóstico para a detecção de anormalidades da pele. Entretanto, pouco sabemos sobre o conhecimento desses profissionais em relação ao uso do filtro solar, tampouco sobre a forma como orientam seus pacientes.

Em função desse contexto, esta pesquisa teve como objetivo analisar o conhecimento de profissionais da beleza sobre a importância dos filtros solares, e como orientam seus pacientes quanto ao uso.

Também nos interessava entender o conhecimento desses profissionais sobre os produtos orgânicos. Atualmente existe um investimento muito grande das indústrias alimentícia e de cosméticos direcionado ao desenvolvimento de produtos de origem vegetal e sem conservantes. Portanto, incluímos essa temática nas entrevistas de forma a entender o conhecimento e o posicionamento dos profissionais em relação aos produtos naturais.

\section{Materiais e métodos}

Elegeu-se como local de estudo o município de Maringá, situado no norte do Paraná, sul do Brasil, devido ao grande número de clínicas e salões de beleza que possui, 196. Realizou-se um estudo 
exploratório-descritivo com abordagem qualitativa, no período de março a setembro de 2013.

A amostra foi aleatória, composta por: 30 profissionais do sexo feminino, idade média de 28 (19 a 41) anos, tecnólogos e técnicos em estética, fisioterapeutas e educador físico. Trabalhavam em clínicas, centros de estética ou salões de beleza que atuam na área de estética facial.

Para a coleta dos dados, os horários das entrevistas foram variados, de manhã e de tarde, de acordo com a agenda do entrevistado e realizada no local de trabalho do mesmo. Os áudios das entrevistas foram registrados em gravador de voz, sendo que cada durou em média 12 minutos.

O questionário foi elaborado com 18 questões abertas. Para testar o instrumento em relação à clareza das perguntas, realizamos um pré-teste com um grupo de 10 profissionais: resultado - na avaliação dos entrevistados e da pesquisadora o instrumento foi considerado satisfatório no sentido de conseguir coletar as informações necessárias para responder os objetivos da pesquisa. Os entrevistados concordaram em participar da pesquisa por meio da assinatura do Termo de Consentimento Livre e Esclarecido (TCLE).

Os dados coletados foram tabulados com o uso do software Atlas.ti, versão 7.1.3, que "permite o manejo dos dados e integra as informações" O software é indicado pela literatura da área ${ }^{8} \mathrm{em}$ função de possuir ferramentas para o tratamento de dados qualitativos na forma de textos com o discurso acerca de temas e questões discutidas oralmente. Os discursos orais foram transformados em textos com reprodução na íntegra e, posteriormente, foram organizados seguindo um processo de codificação e definição das categorias de análise. Dos dados coletados, foram criadas 18 categorias de análise: formação; tempo de experiência; locais de atuação; atividade de formação sobre filtro solar; diferença entre filtro, fotoprotetor e protetor; cuidados; efeitos da exposição; efeito do filtro; utilização profissional; orientação paciente; utilização paciente; faixa etária; gênero; escolha filtro; marca de preferência; filtro natural; restrição aos produtos; câncer de pele.

O estudo foi aprovado pelo comitê de ética e pesquisa do Centro Universitário Cesumar. A elaboração deste estudo procurou atender ao check list de recomendações do Consolidated Criteria For Reporting Qualitative Research (COREQ).

\section{Resultados e discussão}

Em termos de perfil, todos os profissionais pesquisados eram do gênero feminino, com formação variável, na qual a maioria $(83 \%)$ fez curso tecnológico em estética (Tabela 1). Quanto a especializações, grande parte (24) realizou cursos livres voltados para essa área, sendo que sete possuíam especialização concluída e dois ainda cursavam uma especialidade.

Os dados mostram um cenário promissor em termos de mercado de trabalho para esse setor da saúde. A busca pela qualificação profissional formal parece acompanhar a tendência mostrada pela Associação Brasileira da Indústria de Higiene Pessoal, Perfumaria e Cosméticos (ABIHPPC) ${ }^{9}$, a qual mostra que o mercado da estética iniciou uma ascensão entre os anos de 2001 e 2010. O aumento real do PIB do Brasil foi de $41 \%$, enquanto o do setor de Higiene Pessoal, Perfumaria e Cosméticos foi de 70\%, contribuindo de forma expressiva para o desenvolvimento econômico brasileiro. Neste sentido, a atualização profissional vem se mostrando em franco crescimento, possibilitando que o Brasil alcance qualidade nos procedimentos que podem ser cada vez mais aprimorados garantindo ao paciente o tratamento de excelência. Isto se faz necessário principalmente no mercado da estética e da cosmética devido aos novos equipamentos, materiais, cosméticos e tendências que constantemente surgem ${ }^{10}$.

Além da atualização dos profissionais, o tempo de experiência na área de trabalho é de grande importância, sendo que entre as participantes entrevistadas houve grande variação, havendo desde profissionais com menos de um ano de experiência até outras com mais de 10. Em termos de locais de atuação, existe hoje uma diversidade bastante grande. Do grupo pesquisado, a atuação se dá em clínicas de estética, salões de beleza, SPA,

Tabela 1. Distribuição dos profissionais da beleza, segundo formação.

\begin{tabular}{lcc}
\hline & $\begin{array}{c}\text { Número de } \\
\text { participantes }\end{array}$ & $\begin{array}{c}\text { Frequência } \\
(\%)\end{array}$ \\
\hline Tecnólogo em estética & 25 & 83,33 \\
Técnico em estética & 2 & 6,66 \\
Educador Físico & 1 & 3,33 \\
Fisioterapeuta & 3 & 10 \\
Total & 31 & 103,32 \\
\hline
\end{tabular}


lojas de comércio de cosméticos e até mesmo como profissionais liberais fazendo atendimentos domiciliares.

Em relação ao processo de formação continuada, apenas seis $(20 \%)$ declararam participar de eventos (cursos, simpósios, oficinas) sobre filtro solar, enquanto $73 \%$ (22 entrevistadas) relataram presença em eventos não específicos sobre o tema. Este dado pode indicar algumas situações: ou pode refletir a baixa preocupação em buscar informação especializada sobre o tema, ou a carência de cursos mais específicos ou mesmo dificuldades econômicas em realizar cursos e participar em eventos. Porém, são suposições, pois não tivemos dados suficientes para entender esse aspecto. Contudo, em relação ao conhecimento básico acerca dos benefícios do uso do filtro solar, $100 \%$ das entrevistadas afirmaram sua importância na proteção do DNA, na ação antirradical livre, no retardo do envelhecimento, na prevenção de manchas actínias, na inibição da profundidade de rugas, na prevenção ao câncer de pele e na hidratação da pele. Seguem alguns trechos da transcrição das entrevistas:

Com certeza, é muito importante, os tratamentos faciais 70 a $80 \%$ do resultado é devido ao uso correto do filtro solar.

É o melhor cosmético pra você que quer prevenir as suas rugas, o envelhecimento, então, se você não usar ele, pode usar qualquer outro cosmético que não vai fazer efeito.

Uma pessoa que tomou muito sol, se expos muito ao sol e não usou filtro solar, [...] as rugas são muito profundas.

Isto demonstra que os profissionais possuem o conhecimento básico da importância do filtro solar para a prevenção de alterações cutâneas e dos malefícios que podem causar uma exposição prolongada ao sol. Guaratini et al. ${ }^{11}$ ressaltam que a radiação solar provoca efeitos deletérios na pele. A radiação emitida entre 100 e $400 \mathrm{~nm}$ atinge a terra e é capaz de interagir de forma negativa às várias biomoléculas do corpo, gerando inflamação, fotoenvelhecimento e até mesmo o câncer de pele. A utilização de fotoprotetores é de grande importância para proteger a pele de queimaduras solares, fotoenvelhecimento e câncer ${ }^{12}$.

Outra informação relevante foi de uma entrevistada que relatou sua preocupação com as formulações fotoprotetoras:

Ainda existem divergências quanto aos metais pesados que existem na formulação [fotoprotetora] [...] mas enquanto não tem nada comprovado a gente tem que estimular os clientes a usarem.

Isso corrobora as pesquisas que, segundo
Araujo e Souza ${ }^{13}$, afirmam que as duas partículas mais usadas e aprovadas no Japão e nos Estados Unidos são provenientes de metais, o dióxido de titânio e o óxido de zinco. Até o momento, a literatura científica não apresentou estudos que relatem algum tipo de ameaça quanto à utilização destes metais nas formulações cosméticas fotoprotetoras, sendo necessário o desenvolvimento de mais pesquisas para se poder obter um maior conhecimento sobre possíveis eventos adversos na pele.

Os cuidados necessários para que o fotoprotetor obtenha o seu efeito desejado foi pontuado pela maioria dos entrevistados, como: a importância da reaplicação de 2 a 4 horas ou três vezes ao dia de acordo ao fator de proteção, fototipo da pele, exposição à água ou a suor excessivo, higienização da pele no início da aplicação ou reaplicação:

Você usando uma vez por dia [o filtro solar] [...] o efeito é quase nulo, não tem validade

$O$ filtro solar, a gente tem que reaplicar de 2 a 3 horas, a cada 3 horas, mas é bom falar 2 horas porque os clientes vão reaplicar com 3 horas.

Os cuidados menos comentados foram: a utilização de fotoprotetores específicos para a região do corpo, a qualidade do filtro solar, a escolha de marca fidedigna, a armazenagem, a data de validade e as medidas para evitar a contaminação do produto:

Não deixar no carro, expor ao sol, cuidado com a data de validade [...] não deixar aberto, não ficar metendo o dedão nele pra não contaminar o restante que esteja na bisnaga... Na minha opinião, tomando esses cuidados você vai ter um resultado melhor.

Os dados da pesquisa estão em concordância com Milesi e Guterres ${ }^{14}$ que relatam haver uma quantidade mínima necessária a ser empregada para que o produto gere seu efeito, que a reaplicação de 2 a 3 horas também é importante e que é preciso ter cuidado com o FPS. Souza et al. ${ }^{15}$ acrescentam, ainda, que deve-se: evitar tomar sol entre 10 e 15 horas e usar protetores solares com FPS de no mínimo 15. Outros cuidados com o uso do filtro solar são destacados nas bibliografias, como: o aplicar de 20 a 30 minutos antes da exposição solar, utilizar $2,0 \mathrm{mg} / \mathrm{cm}^{2}$ e o reaplicar seguidamente ${ }^{12}$.

O filtro com Fator de Proteção Solar (FPS) 25 bloqueia $96 \%$ da radiação, mostrando que o uso de formulações com fatores de proteção superiores não é necessário, pois o produto pode se tornar mais sensibilizante devido aos constituintes da sua formulação ${ }^{14}$. 
Dentre os efeitos causados pela exposição solar excessiva, o envelhecimento precoce e o câncer de pele foram as alterações mais citadas pelas entrevistadas; mutações no DNA, degradação do colágeno, queimaduras, manchas, insolação, rugas e linhas de expressão foram também relatadas, porém sem muita ênfase. Por outro lado, efeitos benéficos trazidos pela exposição ao sol não foram referidos:

Em horários críticos, horários assim que o sol tá muito alto, que a incidência de raio ela é muito forte, mesmo com filtro, ele pode, não é que ele vai falhar, mas [o filtro solar] pode falhar.

A radiação excessiva num dia, por exemplo, ela pode gerar umas queimaduras, né, pode gerar a questão da vermelhidão de pele, mas com o passar do tempo, né, isso vamos dizer seja rotineiro essa exposição excessiva gera sim problemas como o câncer de pele... Gera problemas com essa questão de mancha na pele, faz o envelhecimento precoce da pele... O envelhecimento é o primeiro que a gente vê, segundo mancha e se tiver a questão hereditária, câncer de pele, pode surgir já em terceiro passo.

As radiações ultravioletas são reconhecidas por autores como responsáveis pelo processo de melanogênese, produção de eritema e processo inflamatório, danos ao DNA celular, fotoimunossupressão. A radiação ultravioleta causa o espessamento do estrato córneo, apresenta potencial carcinogênico e produz radicais livres, sendo que as radiações mais intensas ocorrem no período das 10 às 16 horas $^{12}$.

Um aspecto que traz preocupação é a dificuldade das profissionais em responder se há diferença entre Filtro Solar, Fotoprotetor ou Protetor Solar. Algumas responderam que havia diferença entre esses produtos, mas que não saberiam explicar, já outras tentaram explicar essas diferenças, porém não foram claras nas respostas, enquanto outras não sabiam se havia diferença, e somente uma foi categórica na resposta ao afirmar que não há diferenças. Shalka e Reis $^{6}$ asseguram que filtro solar, fotoprotetor ou protetor solar são nomenclaturas que designam a mesma substância capaz de proteger a pele dos efeitos deletérios da radiação ultravioleta. Apesar de neste caso não haver diferença, isso pode indicar certa confusão conceitual causada pelo uso indistinto, mas que a indústria estética a faz ao nominar seus produtos para que se diferenciem no mercado. Ou seja, a indústria e o mercado, em suas disputas comerciais, não contribuem para a melhoria do entendimento da população e dos profissionais sobre seus produtos do ponto de vista estritamente da saúde.
Quanto à utilização de filtro solar nos atendimentos clínicos faciais, todas as profissionais responderam que utilizavam para finalizar seus procedimentos. E quando perguntadas se os pacientes utilizam o filtro solar diariamente, 50\% das entrevistadas afirmaram que sim, porém desconheciam se haveria reaplicação. A faixa etária dos pacientes atendidos pelas profissionais que utilizam fotoprotetores diariamente variava de 15 a 60 anos, porém a maior frequência é de pessoas que já possuíam alguma alteração de pigmentação ou sinais de envelhecimento. Com isso, tendemos a pensar que a procura por tratamentos tenha se dado em função dessas alterações de pele e não como um hábito de prevenção.

O gênero que mais utiliza o filtro solar, segundo os entrevistados, é o feminino, embora alguns pesquisados tenham exposto que tem havido um crescimento da procura pelo sexo masculino por tratamentos estéticos e na utilização. Contudo, segundo as entrevistadas, a procura por profissionais de saúde e estética ainda é maior pelo público feminino, dado corroborado por outros estudos ${ }^{16,17}$ :

Olha, homem é mais teimoso, é mais indisciplinado, e quase não usa nada de cuidados diários, totalmente zero, só alguns, né que são mais vaidosos, que têm mais preocupação com a saúde e o bem estar que utilizam, mas com certeza é a mulher que cuida mais, mas mesmo assim deixa a desejar.

Todas as entrevistadas afirmaram orientar os pacientes quanto aos riscos e benefícios da exposição solar e como utilizar corretamente o filtro solar:

Indico porque ele vai prevenir 70 a $80 \%$ de todos os problemas que depois elas vão procurar outros cosméticos pra reparar.

Quando perguntados como ocorria a escolha do filtro solar, as respostas se revelaram conforme mostrado na Tabela 2. A totalidade (30) escolhe pela qualidade do produto, sendo a textura e

Tabela 2. Escolha do filtro solar pela profissional, segundo atributos do produto.

\begin{tabular}{lcc}
\hline Atributos & $\begin{array}{c}\text { Número de } \\
\text { participantes }\end{array}$ & $\begin{array}{c}\text { Frequência } \\
\text { relativa }\end{array}$ \\
\hline Marca & 8 & 19,5 \\
Preço & 3 & 7,31 \\
Qualidade & 30 & 73,1 \\
Total & 41 & 100 \\
\hline
\end{tabular}


os ativos presentes na formulação fotoprotetora os mais valorizados. Os dados revelaram um total de 41 respostas, isto se deu em função de que cada entrevistada indicou mais de um aspecto utilizado na escolha do produto.

Dentre as entrevistadas, oito responderam que na escolha do filtro solar prezavam pela marca, ou seja, colocavam em primeiro lugar a valorização do produto no mercado de cosmético, e por último o preço do produto. Isso se mostrou interessante, pois a composição do valor final do procedimento estético depende do valor dos produtos que são utilizados, mas mesmo assim a qualidade do tratamento foi colocada acima dos interesses econômicos.

A qualidade de um fotoprotetor é determinada por meio das características físico-químicas presentes na formulação garantindo que o produto se espalhe melhor, tenha resistência à água e substantividade ${ }^{14}$. A marca de preferência escolhida pelos profissionais foi a ADCOS (18), seguida pela Spa da Pele (4) A marca de preferência relatada pelos profissionais justifica-se, dito por eles, como sendo uma marca com bom preço, boa qualidade, boa textura e adaptável a quase todos os tipos de pele.

Referente sobre o atendimento a pacientes com suspeita ou presença de câncer de pele, $87 \%$ das profissionais nunca atenderam e quatro suspeitaram de câncer de pele. Todas as profissionais entrevistadas disseram encaminhar e não atender tratamentos estéticos caso detectassem câncer de pele na primeira sessão de tratamento.

Em 2010, no Brasil, 115.000 novos casos de câncer de pele não melanoma foram diagnosti$\operatorname{cados}^{18}$, por isto o encaminhamento ao profissional especializado quando suspeito de alguma alteração cutânea é fundamental, pois as lesões possuem chances de cura quando tratadas precocemente.

Ao questionamento do conhecimento do profissional quanto à existência de filtro solar com componentes antirradicais livres naturais na composição do produto a maioria $(83,33 \%)$ não possuía esse conhecimento, e $16,66 \%$ não souberam responder, pois não recordavam.

Além do interesse da sustentabilidade e da utilização de produtos orgânicos, Ferrari et al. ${ }^{19}$ revelam quão importante é o uso de produtos com componentes naturais, pois estes são bio- degradáveis, não possuem corantes, conservantes, aromatizantes ou outros aditivos sintéticos, sendo benéficos à saúde do consumidor por reduzir o risco de alergias, prurido e dermatites. São necessários estudos que permitam a criação de filtros solares com componentes naturais para garantir uma eficácia maior quanto à proteção solar e cuidados cutâneos. Dentre os entrevistados ninguém estava utilizando fotoprotetores solares preparados com produtos naturais, apenas com de origem sintética.

Em relação ao interesse do uso de fotoprotetores com princípio ativo natural na formulação, 86,67\% dos profissionais relataram não ter restrição em utilizá-los, $3(10 \%)$ teriam pouca restrição e somente um $(3,33 \%)$ que não utilizaria, porém aqueles com pouca restrição afirmam poder utilizar para testar sua eficácia.

\section{Conclusões}

Os resultados obtidos evidenciaram que entre as profissionais entrevistadas está havendo uma utilização consciente dos filtros solares, mostrou ainda que elas possuem um bom conhecimento sobre estes e sobre a importância e a necessidade desse produto para a prevenção de neoplasias cutâneas. Devido a dificuldades que as profissionais tiveram em responder se havia diferença entre Filtro Solar, Fotoprotetor ou Protetor Solar, seria interessante a realização de cursos periódicos para aumentar o nível de conhecimento destes produtos. Também mostrou o comprometimento das profissionais em orientar seus usuários para a utilização correta do fotoprotetor tópico. Porém, estudos abrangentes com amostras mais amplas acerca deste tema são necessários devido às limitações da pesquisa.

\section{Colaboradores}

DAG Cortez, ES Machado, SCSD Vermelho, JJV Teixeira e LER Cortez participaram igualmente de todas as etapas de elaboração do artigo. 


\section{Referências}

1. Ludgleydson A, Sa ECN, Amaral EB. Corpo e velhice: um estudo das representações sociais entre homens idosos. Psicologia: Ciência e Profissão 2011; 31(3):468481.

2. Instituto Nacional de Câncer (INCA). Prevenção e controle do câncer: normas e recomendações do INCA. Rev Bras Cancerol 2002; 48(3):317-332.

3. Souza RJSAP, Mattedi A, Rezende M, Corrêa MP, Duarte EM. Estimativa do custo do tratamento de câncer de pele tipo melanoma no Estado de São Paulo - Brasil. An Bras Dermatol 2009; 84 (3):237-243.

4. Ferreira FR, Nascimento LFCO. Risk factors for nonmelanoma skin cancer in Taubaté, SP: a case-control study. Rev Assoc Med Bras 2011; 57(4):431-437.

5. Nora AB, Panarotto D, Lovatto L, Boniatti MM. Freqüência de aconselhamento para prevenção de câncer da pele entre as diversas especialidades médicas em Caxias do Sul. An Bras Dermatol 2004; 79(1):45-51.

6. Schalka S, Reis VMS. Sun protection factor: meaning and controversies. An. Bras. Dermatol. 2011; 86(3):507515.

7. Silva AMTB, Constantino GD, Premaor VB. A contribuição da teoria das representações sociais para análise de um fórum de discussão virtual. Temas em Psicologia 2011; 19(1):233-242.

8. Gibbs G. Análise de dados qualitativos. Porto Alegre: Artmed; 2009.

9. Associação Brasileira da Industria de Higiene Pessoal, Perfumaria E Cosméticos (ABIHP). Por um Brasil com Saúde e mais Bonito: a contribuição do setor de Higiene Pessoal, Perfumaria e Cosméticos para o desenvolvimento do país. 2011. [acessado 2013 out 25]. Disponível em: http://www.abihpec.org.br/wp-content/uploads/2012/01/Por-um-Brasil-maisBonito_vf

10. Marques ELSS, Silva PM, Costa HC. O mercado da beleza. Cadernos Temáticos de Ciências Gerenciais: Textos para Reflexão 2004; 5(1):8-10.

11. Guaratini T, Callejon DR, Pires DC, Lopes JNC, Lima LM, Giannella-Neto D, Sustovich C, Lopes NP. Fotoprotetores derivados de produtos naturais: perspectivas de mercado e interações entre o setor produtivo e centros de pesquisa. Quím Nova 2009; 32(3):717-721.
12. Tofetti MHFC, Oliveira VR. A importância do uso do filtro solar na prevenção do fotoenvelhecimento e do câncer de pele. Rev Científica da Universidade de Franca 2006; 6(1):59-66.

13. Araujo S, Souza SO. Protetores solares e os efeitos da radiação ultravioleta. Scientia Plena 2008; 4 (11):1-7.

14. Milesi SS, Guterres SS. Fatores determinantes da eficácia de fotoprotetores. Cad de Farmácia 2002; 18(2):8187.

15. Souza SLG, Braganholo LP, Ávila ACM, Ferreira AS. Recursos Fisioterapêuticos Utilizadosno Tratamento do Envelhecimento Facial. Rev Fafibe On Line 2007; 1(3):1-12.

16. Castilho IG, Sousa MAA, Leite RMS. Photoexposure and risk factors for skin cancer: an evaluation of behaviors and knowledge among university students. An Bras Dermatol 2010; 85(2):173-178.

17. Szklo AS, Almeida LM, Figueiredo V, Lozana JA, Mendonça GAS, Moura L, Szklo M. Comportamento relativo à exposição e proteção solar na população de 15 anos ou mais de 15 capitais brasileiras e Distrito Federal, 2002-2003. Cad Saude Publica 2007; 23(4):823-834.

18. Chinem VP, Miot HA. Epidemiologia do carcinoma basocelular. An Bras Dermatol 2011; 86(2):292-305.

19. Ferrari M, Oliveira MSC, Nakano AK, Rocha-Filho PA Determinação do fator de proteção solar (FPS) in vitro $\mathrm{e}$ in vivo de emulsões com óleo de andiroba (Carapa guianensis). Rev bras farmacogn 2007; 17(4):626-630.

Artigo apresentado em 26/05/2015

Aprovado em 22/08/2015

Versão final apresentada em 24/08/2015 
